\title{
In reply: Comments on "Anesthesia for interventional pulmonology procedures: a review of advanced diagnostic and therapeutic bronchoscopy"
}

\author{
Andres de Lima, MD • Fayez Kheir, MD, MSCR • Adnan Majid, MD, FCCP • \\ John Pawlowski, MD, PhD $\mathbb{D}$
}

Received: 14 May 2018/Revised: 18 May 2018/Accepted: 18 May 2018/Published online: 6 June 2018

(C) Canadian Anesthesiologists' Society 2018

\section{To the Editor,}

We appreciate the interest from Dr. Biro ${ }^{1}$ in our article addressing the anesthetic and other related implications of interventional pulmonology procedures, ${ }^{2}$ in particular, the specific comments regarding jet ventilation. With respect to the Venturi effect, we agree completely that this phenomenon, which resembles entrainment, would tend to decrease the fraction of inspired oxygen and increase the delivered tidal volume. Regarding driving pressure, in our clinical practice, we find that manipulation of the driving pressure is the most reliable way to adjust ventilation. Our use of the term "conventional ventilation periods" refers to a switching of the ventilator to a low frequency ventilator with a semi-closed circuit and end-tidal $\mathrm{CO}_{2}$ monitoring to ascertain the $\mathrm{CO}_{2}$ level. In the special circumstance where obstruction prevents the outflow of gas, your comment that "the real protection against barotrauma is continuous measurement of the airway pressure using a separate [distal] lumen" is extremely valuable. While we do agree with the "safety feature" of the automatic shutdown, we are not aware of any published evidence. Your comments

A. de Lima, MD - F. Kheir, MD, MSCR - A. Majid, MD, FCCP Division of Thoracic Surgery and Interventional Pulmonology, Beth Israel Deaconess Medical Center, Harvard Medical School, Boston, MA, USA

\section{A. Majid, MD, FCCP}

Division of Pulmonary Diseases, Critical Care and

Environmental Medicine, Tulane University Health Sciences

Center, New Orleans, LA, USA

J. Pawlowski, MD, PhD $(\bowtie)$

Division of Thoracic Anesthesia, Department of Anesthesia,

Beth Israel Deaconess Medical Center, Boston, MA, USA

e-mail: jpawlows@bidmc.harvard.edu about auto-positive end-expiratory pressure not being a major contributor to barotrauma in these cases conform to those in our original article. In addition, your remarks about dry gas during short cases and the benefits of humidification during long cases are also shared. We thank you for bringing attention to these useful clinical aspects of jet ventilation in interventional pulmonary procedures.

Conflicts of interest None declared.

Editorial Responsibility This submission was handled by Dr. Hilary P. Grocott, Editor-in-Chief, Canadian Journal of Anesthesia.

\section{References}

1. Biro P. Comments on "Anesthesia for interventional pulmonology procedures: a review of advanced diagnostic and therapeutic bronchoscopy". Can J Anesth 2018; 65. DOI: https://doi.org/10. 1007/s12630-018-1168-1

2. de Lima A, Kheir F, Majid A, Pawlowski J. Anesthesia for interventional pulmonology procedures: a review of advanced diagnostic and therapeutic bronchoscopy. Can J Anesth 2018. DOI: https://doi.org/10.1007/s12630-018-1121-3. 